\title{
Relacionismo Substancial: A Ontologia do Comportamento à Luz do Behaviorismo Radical.
}

\author{
Diego Zilio $^{1}$ \\ Universidade de São Paulo
}

\begin{abstract}
RESUMO - Sob a influência do pragmatismo e contextualismo pepperiano, analistas do comportamento extraíram do behaviorismo radical qualquer posição ontológica. Como resultado, há a defesa de um relacionismo radical no qual a única propriedade relevante para a existência do comportamento é a própria relação que o define. O objetivo deste ensaio é avaliar a pertinência dessa posição. Três questões guiram esse trabalho: (1) Por que a substância não é importante para o behaviorismo radical?; (2) Por que a substância é importante para o behaviorismo radical?; e (3) Qual seria, de fato, o posicionamento ontológico mais condizente com o behaviorismo radical? Argumenta-se que o relacionismo radical não reflete com acurácia a ontologia behaviorista radical e sugere-se que o relacionismo substancial seja a posição mais coerente.
\end{abstract}

Palavras-chave: Behaviorismo radical; Skinner; Comportamento; Ontologia; Relacionismo; Substância.

\section{Substantial Relationism: The Ontology of Behavior from the Perspective of Radical Behaviorism.}

\begin{abstract}
Influenced by pragmatism and pepperian contextualism, some behavior analysts have denied any ontological assumption concerning substance to radical behaviorism. As a result, a radical version of relationism is defended in which the only property relevant to the existence of behavior is the very relation that defines it. The aim of this paper is to evaluate the pertinence of that position. Three questions will guide our analysis: (1) Why is substance not important to radical behaviorism?; (2) Why is substance important to radical behaviorism?, and (3) What is, in fact, the ontological attitude more consistent with radical behaviorism? It is argued that extreme relationism does not accurately reflect radical behavioristic ontology and it is suggested that substantial relationism is a more coherent position.
\end{abstract}

Keywords: Radical behaviorism; Skinner; Behavior; Ontology; Relationism; Substance.

O que propomos neste ensaio é um exercício metafísico acerca da ontologia do comportamento a partir da perspectiva behaviorista radical. Normalmente, caracteriza-se como metafísica a parte da filosofia que busca compreender a natureza da realidade última e transcendente (Hamlyn, 1995; Inwagen, 2007). Nesse sentido, discussões ontológicas são discussões metafísicas. Lowe (1995) sustenta que a ontologia é o ramo da metafísica que lida com questões "tais como a da natureza da existência e a da estrutura categórica da realidade” (p. 634). Sendo assim, tratar da ontologia do comportamento implica em discorrer sobre a sua natureza essencial, ou seja, sobre as propriedades essenciais à sua existência.

Nesse contexto, a partir de análises "pragmatistas" e "contextualistas pepperianas", extraiu-se do behaviorismo radical qualquer posição ontológica substancialista (Abib, 2001, 2004; Barnes \& Roche, 1994, 1997; Barnes-Holmes, 2000, 2005; Baum, 1994/1999; Hayes, 1997; Krägeloh, 2006; Leigland, 2004) $)^{2}$. Para esses autores, o behaviorismo

1 Endereço para correspondência: Laboratório de Análise Biocomportamental - Departamento de Psicologia Experimental - USP. Av. Prof. Mello Moraes, 1721; CEP 05508-900 São Paulo-SP-Brasil.Telefone: (11) 3091-4444, ramal 210;E-mail: dzilio@usp.br

2 Entretanto, é importante ressaltar que essa conseqüência não é necessária. Moxley (2001a, 2001b; 2002a, 2002b, 2004), por exemplo, tem obra extensa sobre as relações entre o behaviorismo radical e o pragmaticismo de Peirce, mas o autor não defende a posição que definiremos adiante de "relacionismo radical". radical estaria fundado numa ontologia relacionista, de acordo com a qual a única propriedade relevante para a existência do comportamento é a própria relação que o define. Como resultado, nas palavras de Abib (2001), “[...] o fisicalismo ontológico é estranho ao behaviorismo radical. Logo, não há alternativa a não ser radicalizá-lo e eliminar de seu corpo teórico o fisicalismo ontológico e de seu vocabulário os termos comprometidos com essa ontologia” (p. 31). Denominaremos aqui essa posição de "relacionismo radical".

Mas por que tal radicalização seria necessária? O problema da ontologia substancialista estaria em sua aparente desconsideração pela natureza relacional do comportamento (Abib, 2001, 2004; Barnes \& Roche, 1997; Baum, 1994/1999). E isso seria um problema porque a ontologia substancialista é característica inextrincável do fisicalismo.

O fisicalismo é constituído por três teses (Zilio, 2010). A "tese central" fisicalista consiste na suposição de que o único mundo que existe, o único mundo que é real, é o mundo físico. Há duas teses auxiliares que acompanham a tese central. A primeira delas é a "tese da constituição", de acordo com a qual o mundo físico é o mundo dos eventos físicos, que, por sua vez, são constituídos por entidades microfísicas em si ou por entidades macrofísicas realizadas/compostas/constituídas por entidades microfísicas. E a segunda delas é a "tese da causalidade", segundo a qual os eventos físicos possuem propriedades físicas e são essas propriedades as responsáveis pelas relações causais no mundo físico, o que significa 
que todo evento-efeito físico possui um evento-causa físico suficiente para sua ocorrência (Zilio, 2010).

A tese central do fisicalismo é o que denominaremos aqui de "ontologia substancialista". A tese da constituição, por sua vez, indica a definição de substância com a qual iremos trabalhar: a substância de algo é o que o constitui (Robinson, 2009). Assim, por exemplo, para Descartes (1641/1984) a mente não é constituída por substância física, mas possui natureza substancial própria. Para os fisicalistas, por outro lado, a mente é o cérebro, e esse sim é constituído por substância física (e.g. Churchland, 1986). Mas é na tese da causalidade que encontramos o problema do fisicalismo: supor que as relações causais entre eventos devam ser explicadas pelas propriedades físicas substanciais que os compõem; idéia essa que é incompatível com o relacionismo skinneriano (Abib, 2001, 2004; Chiesa, 1994; Kitchener, 1977; Moore, 2008; Zilio, 2009).

A gênese dessa incompatibilidade está na própria definição de reflexo proposta por Skinner (1931/1961a), segundo a qual o reflexo seria uma "correlação observada entre um estímulo e uma resposta" (p. 442). Nessa perspectiva, o estímulo só poderia ser definido em função da resposta e a resposta em função do estímulo. Transpondo o relacionismo para o âmbito ontológico: não existe estímulo sem resposta ou resposta sem estímulo 3 (Barnes \& Roche, 1994, 1997; Barnes-Holmes, 2000, 2005). Embora esta não seja uma conseqüência necessária, a definição relacional proposta por Skinner acabou por fundamentar o relacionismo radical, distanciando, assim, o behaviorismo radical da ontologia substancialista. Afinal, se o comportamento é definido como um processo relacional de fluxo contínuo entre o ambiente e as ações de um organismo (Skinner, 1953/1965, 1954), e se os próprios estímulos e respostas que compõem, respectivamente, o ambiente e as ações, só existem enquanto tais na própria relação, então o comportamento só existe enquanto processo relacional - essa seria a sua natureza essencial. Concluindo com Barnes e Roche (1994): “A realidade não é nem o universo físico e nem o domínio do mental. A realidade é uma interação comportamental - não é nem o estímulo e nem a resposta, mas sua interação co-definidora" (p. 168).

Para o relacionismo radical, não há sentido em postular que a realidade é constituída por substância física ${ }^{4}$. Tampouco há sentido em defender que a realidade é constituída por substância mental. Em última instância, pode-se dizer que a realidade seria pura relação comportamental. Nota-se que a passagem supracitada de Barnes e Roche (1994) abarca o problema metafísico da natureza da realidade. Como o nosso foco aqui é a natureza do comportamento, que faz parte da realidade, é possível supor que o argumento é o mesmo: o comportamento não seria constituído nem por substância física e nem por substância mental, sendo a sua essência a própria relação que o define.

3 É importante ressaltar que no início de suas pesquisas, mesmo após o estudo com operantes, Skinner utilizava o termo "reflexo" num sentido mais geral, envolvendo qualquer processo comportamental. Portanto, é possível sustentar que a definição relacional de "reflexo" é na verdade uma definição relacional do comportamento como um todo.

4 Kitchener (1977) chegou à conclusão semelhante ao afirmar que a "a crença no fisicalismo parece não possuir papel crucial nesse paradigma [behaviorista radical]"' (p. 64).
O objetivo deste ensaio é justamente avaliar a pertinência do relacionismo radical como característica da ontologia behaviorista radical tendo como base os textos de Skinner. Há três questões norteadoras da nossa investigação e este ensaio está dividido de acordo com elas: (1) Por que a substância não é importante para o behaviorismo radical?; (2) Por que a substância é importante para o behaviorismo radical?; e (3) Qual seria, de fato, o posicionamento ontológico mais condizente com o behaviorismo radical? A partir da análise dos argumentos de Skinner supostamente contrários e favoráveis à ontologia substancialista, espera-se que seja possível extrair as características de uma ontologia propriamente behaviorista radical.

\section{A suposta negação da substância no behaviorismo radical}

Parece existir certa ambigüidade na obra de Skinner no que tange à ontologia substancialista. Por um lado, em diversos momentos o autor faz questão de salientar que o comportamento é constituído por substância física (Skinner, $1935 / 1961$ b, p. $355 ; 1945 / 1961$ c, p. $285 ; 1953 / 1965$, p. 36; 1954 , p. $304 ; 1956 / 1961$ d, p. $206 ; 1966$ b, p. 1205; 1967, p. $325 ; 1974$, p. 220 , p. $233 ; 1975$, p. $42 ; 1979$, p. 295), ao passo em que, por outro lado, também supostamente nega sua relevância no estudo do comportamento (Skinner, 1938/1966a, p. 4; 1953/1965, p. 138; 1963, p. 951; 1969a, p. 248; 1987, p. 780). Como tratar essa ambigüidade? Só uma análise cuidadosa das obras em que Skinner expõe suas idéias pertinentes ao tema poderá nos indicar o caminho.

Comecemos, então, pelas passagens de Skinner que parecem sugerir uma posição crítica à ontologia substancialista. Conforme veremos a seguir, tais passagens não suportam necessariamente essa conclusão, mas apenas reafirmam o caráter relacional que define o comportamento e o aspecto prático por detrás da filosofia da ciência behaviorista radical.

[Um] problema no controle por estímulos tem atraído mais atenção do que merece por causa de especulações metafisicas sobre o que está 'realmente lá' no mundo de fora. $O$ que acontece quando um organismo responde 'como se' um estímulo tivesse outras propriedades? Esse comportamento parece indicar que o mundo 'perceptual' - o mundo tal como o organismo o experiencia - é diferente do mundo real. Mas, na verdade, a diferença é entre respostas - entre respostas de dois organismos ou entre respostas de um organismo sob modos diferentes de estimulação a partir de um único estado de coisas. (1953/1965, p. 138)

Em outra passagem:

$O$ argumento dualista sucede da seguinte da forma. Nós não conhecemos o mundo tal como ele é, mas apenas como ele parecer ser. Nós não podemos conhecer o mundo real porque ele está fora do nosso corpo, em grande parte à distância. Conhecemos apenas cópias que estão dentro dos nossos corpos. [...] Se aceitamos a posição grega de que só podemos conhecer apenas nossas sensações e percepções, [então] há apenas um mundo, e este é o mundo da mente. É muito simples parafrasear 
a alternativa behaviorista dizendo que há, de fato, apenas um mundo e que este é o mundo da matéria, pois o termo 'matéria' não é mais útil. Seja qual for a substância da qual o mundo é feito, ele contém organismos (dos quais nós somos exemplos) que respondem a outras partes dele [do mundo] e, assim, 'conhecem' em um sentido não muito distante de [entrar em] 'contato'. Nas situações em que o dualista precisa considerar discrepâncias entre o mundo real e o mundo da experiencia, e o idealista berkeleano entre experiências diferentes, o behaviorista investiga discrepâncias entre respostas diferentes. (1969a, pp. 247-249)

Essas duas passagens sugerem que Skinner seria avesso à ontologia substancialista. Mas por quê? São as "especulações metafísicas" sobre como explicar a relação entre "mundo real" e "mundo da experiência", bem como as discrepâncias que podem ocorrer no processo - quando, por exemplo, um sujeito experiencia algo que não está no "mundo real", mas é "como se estivesse no mundo real" - que estão em pauta. Em outras palavras, Skinner está lidando com o problema da representação e com o problema do conhecimento. $\mathrm{O}$ autor (1969a) apresenta duas abordagens. Há o ponto de vista dualista, que leva esse nome por sustentar a existência de dois mundos: o "mundo real", que é o mundo físico, e o "mundo da experiência", que é o mundo da mente. Na verdade, Skinner $(1953 / 1965 ; 1969 a ; 1974 ; 1985)$ relaciona o dualismo com a teoria representacionista da percepção, segundo a qual não seria o mundo real a ser percebido, mas sim cópias ou representações desse mundo construídas na mente do observador. Aos dualistas apresentam-se dois problemas: como ocorre a relação entre representação ("mundo da experiência") e objeto percebido ("mundo real")?; e como explicar as discrepâncias entre representação e realidade? $\mathrm{O}$ argumento central do idealismo, por sua vez, é que existe apenas a mente, sendo o mundo real uma ilusão criada por ela. Dessa forma, haveria um monismo, mas um monismo mental. Não haveria representação da realidade, tal como no dualismo, mas unicamente a realidade mental. Restaria somente responder como e por que existem discrepâncias entre percepções e sensações distintas dentro do mundo monista mental.

Na passagem supracitada, Skinner (1969a) conclui que seria muito "simples" apresentar o behaviorismo radical como teoria materialista, pois o termo "matéria" perdeu importância. O que o autor quer dizer como isso? Primeiramente, é importante ressaltar que tanto o dualismo quanto o idealismo são teses sobre a natureza substancial do mundo. Para o primeiro há duas substâncias, a mental e a física, e para o segundo há apenas a substância mental. Qual seria a terceira opção? Naturalmente, a única que falta é a de que existe apenas uma substância, a física. Todavia, Skinner (1969a) segue este rumo em sua argumentação: é muito "simples" dizer que o behaviorismo radical é monista fisicalista. O que justifica esse ato? Poderíamos sugerir que a posição de Skinner reflete seu desinteresse pela metafísica: para o behaviorismo radical talvez não importe qual seja a natureza substancial do mundo (cf. Skinner, 1956/1961d, p. 209; 1969a, p. 248; 1987, p. 780) ${ }^{5}$. Mas essa interpretação

5 Iremos discutir essa possibilidade adiante no texto. não seria suficiente, pois ainda precisaríamos esclarecer a justificativa para esse posicionamento.

Nesse caso, a chave para entender a posição de Skinner está na primeira citação apresentada anteriormente: as discrepâncias encontradas no processo perceptivo devem ser explicadas a partir das contingências de reforço (Skinner, 1953/1965). O mesmo "estado de coisas" pode constituir estímulos funcionalmente diferentes. Um objeto físico com propriedades físicas específicas, por exemplo, pode servir de estímulo discriminativo ou, até mesmo, de estímulo eliciador para respostas perceptuais das mais diversas. O que importa é a história de reforçamento responsável pelo repertório comportamental dos sujeitos. Nas palavras de Skinner (1974): "pessoas vêem coisas diferentes quando estiveram expostas a diferentes contingências de reforço" (p. 79). Se há discrepâncias entre como um sujeito $S 1$ e um sujeito $S 2$ respondem ao mesmo estado de coisas - que, nesse caso, constituiria dois estímulos diferentes, um para $S 1$ e outro para $S 2$ - é só porque as classes comportamentais de $S 1$ e de $S 2$ devem ser funcionalmente diferentes. Skinner parece sugerir que as especulações metafísicas sobre a natureza substancial do mundo não são importantes na medida em que as explicações estão nas contingências e não nos "estados de coisas" que as constituem (cf. Tonneau, 2005a, 2005b; Zuriff, 1985). É exatamente nesse sentido que o termo "matéria" perdeu importância, pois a defesa do monismo fisicalista, por si só, não ajudaria nas explicações do comportamento.

Há, porém, um ponto que devemos ressaltar. O behaviorismo radical é veementemente contrário à teoria representacionista da percepção e do conhecimento. Conhecimento não é contemplação, não é algo que um sujeito possui e estoca em sua mente para uso futuro. Conhecimento é uma relação de controle do ambiente sobre o sujeito, que, então, não o conhece por conta de um ato puro de sua vontade ou desejo, mas porque certas características desse ambiente controlam o seu comportamento (Skinner, 1953/1965, 1974). A percepção, por sua vez, é apresentação e não representação (Skinner, 1985). O observador não cria cópias mentais do mundo percebido. Sendo assim, mesmo sem especulações metafísicas, a teoria dualista não é posição cabível no behaviorismo radical. A defesa da existência de um "mundo mental" em adição à existência de um "mundo físico", que além de tudo se relacionam entre si, traz consigo teses como a da representação e do conhecimento - sobre as quais o behaviorismo radical é, em princípio, incompatível. Nas palavras de Skinner (1988): "É a essência do behaviorismo argumentar que uma pessoa não internaliza o mundo ou faz cópias dele [...] e que o comportamento que aparenta precisar de uma representação interna deve ser explicado de outra forma" (p. 213).

Portanto, é possível supor que não importa qual seja a natureza substancial do mundo - física, mental ou qualquer outra - esse mundo deve conter apenas uma delas. O dualismo substancial parece não ser posição compatível com as explicações behavioristas radicais do comportamento. Temos, então, o primeiro indício da ontologia behaviorista radical: a negação do dualismo substancial (cf. Carvalho Neto, 2001; Carrara, 2005; Hocutt, 1996; Moore, 1994, 2008; Schnaitter, 1984; Zuriff, 2003). 
Em tempo, continuemos com outra passagem de Skinner (1987) que insinua uma suposta crítica à ontologia substancialista:

Por mais de 2.500 anos filósofos e psicólogos têm discutido sobre a natureza dessa substância [mental], mas para os propósitos atuais nós podemos aceitar a dissolução que apareceu na Punch em 1855: O que é matéria? - Never Mind. O que é mente? - No Matter. Mente ou matéria, era algo dentro da pessoa que determinava o que ela fazia". $(p .780)^{6}$

Nessa passagem Skinner parece reafirmar seu suposto desinteresse pelas discussões sobre a ontologia substancialista. O que está em questão, porém, é o problema do agente interno iniciador do comportamento - a idéia de que é algo dentro da pessoa, algum tipo de causa interna originária, que controla o comportamento (Zuriff, 1975). Em linhas gerais, não importa se a mente seja algo imaterial ou algo físico, pois as teorias mentalistas ainda explicam o comportamento em função de causas internas. No mesmo texto, Skinner (1987) observa que o erro na psicologia é que "o comportamento é raramente considerado como um objeto de estudo em si mesmo, mas é antes considerado como mera expressão ou sintoma de acontecimentos mais importantes internos à pessoa que se comporta" (p. 780). Em outra passagem o autor (1988) afirma que "a questão crucial no behaviorismo não era o dualismo; mas sim a origem" (p. 245). Em síntese, as explicações do comportamento devem ser buscadas na história filogenética e ontogenética do organismo (Skinner, 1981, 1988). Elas não estão dentro do organismo. É evidente que um organismo que carrega consigo a história filogenética de sua espécie e que passou por uma história ontogenética singular é um organismo fisiologicamente modificado. Mas a explicação do comportamento não está na estrutura que compõe o organismo, invariavelmente caracterizada como algo que está dentro dele, mas sim na própria história. Não é relevante se o agente interno seja "mental cartesiano" ou "mental cerebral" , pois as explicações estão na história filogenética e ontogenética do organismo - elas estão no comportamento enquanto processo relacional. Isso significa que não importa se a substância que compõe a "mente" possua natureza própria, tal como Descartes defendia; tampouco importa se a substância que compõe a "mente" seja física, tal como os fisicalistas supõem. Afinal, ambas as alternativas estariam erradas em sugerir que as causas do comportamento estão dentro do organismo.

Prosseguindo com a análise das passagens em que Skinner parece sustentar desinteresse pela ontologia substancialista:

Eu não quero levantar a questão da suposta natureza dessas entidades internas. [...] se há aqueles que acreditam que a psiquiatria preocupa-se com um mundo para além do organismo psicobiológico ou biofísico, que a mente, consciente e inconsciente, não possui extensão física, e que os processos

6 Decidimos manter algumas partes da citação em inglês, pois se fossem traduzidas perderiam o sentido que Skinner quer ressaltar.

7 Aqui devemos considerar a psicologia influenciada pelas neurociências. É o que Skinner (1987) faz: "Psicólogos cognitivos gostam de dizer que "a mente é o que o cérebro faz"” (p. 784). mentais não afetam o mundo de acordo com as leis da física, então os argumentos seguintes devem ser tanto mais convincentes. A questão não é a da natureza desses eventos, mas sim a de sua utilidade e conveniência numa descrição científica. (1956/1961d, pp. 209-210)

E mais:

O problema básico não é a natureza da substância da qual o mundo éfeito, ou se o mundo é feito de uma ou duas substâncias, mas sim a dimensão das coisas estudadas pela psicologia e os métodos relevantes para elas. [...] A objeção não é que essas coisas são mentais, mas que elas não oferecem explicação real e ficam no caminho de uma análise mais efetiva. (1963, p. 951)

Essas passagens trazem à tona duas questões essenciais e inseparáveis: o behaviorismo radical enquanto filosofia da ciência e a efetividade da explicação comportamental. Nesse contexto, a questão chave que se coloca é a seguinte: qual é o propósito da ciência do comportamento? Para o behaviorismo radical, o principal propósito, senão o único, do conhecimento científico é possibilitar a manipulação efetiva do mundo natural. Essencialmente, o objetivo da ciência do comportamento é manipular as variáveis relacionadas ao fenômeno estudado e, a partir dos dados obtidos nesse processo, criar condições para a previsão e para o controle do comportamento (Skinner, 1953/1965). Em diversos momentos Skinner ressalta essa característica de sua filosofia da ciência: "Conhecimento científico é o que as pessoas fazem ao prever e controlar a natureza" (1956/1961d, p. 215); “A ciência é em grande parte uma análise direta dos sistemas reforçadores encontrados na natureza; sua preocupação é facilitar o comportamento reforçado por eles" (1969a, p. 143); e "O ponto da ciência [...] é analisar as contingências de reforço encontradas na natureza e formular regras ou leis com as quais se torna desnecessário expor-se a elas a fim de se comportar efetivamente" (1969a, p. 166). Em outras palavras, a ciência nos permite conhecer de maneira acurada as contingências presentes no mundo; e a atividade científica é indispensável para o "aprimoramento" de nossas classes comportamentais no sentido de contribuir para o aumento da probabilidade de ocorrência de conseqüências reforçadoras. $\mathrm{O}$ aumento da ocorrência de conseqüências reforçadoras indica, por sua vez, que estamos agindo efetivamente no mundo. Nesse sentido, o valor da ciência é essencialmente prático $^{8}$. É por isso que Skinner $(1969 a, 1979)$ defende que as primeiras regras "científicas" talvez tenham sido os conselhos baseados na experiência empírica ("rules of thumb") dos artífices, que serviam bem aos propósitos práticos que os trabalhos exigiam. No entanto, embora a ciência tenha se desenvolvido a ponto de abarcar as mais complexas contingências do nosso mundo, o princípio ainda permanece o mesmo: promover a ação efetiva (cf. Chiesa, 1994; Hayes \&

8 Nesse caso, poderíamos dizer que a filosofia behaviorista radical é "pragmática" ou "pragmatista". Todavia, Skinner nunca afirmou ser adepto do pragmatismo (Bjork, 1993). Portanto, embora semelhanças possam ser traçadas, talvez seja mais parcimonioso afirmar que há acima de tudo um caráter "prático", ao invés de propriamente "pragmático", na filosofia behaviorista radical. 
Brownstein, 1986; Moore, 1984, 2008, 2010; Smith, 1986, 1992; Zuriff, 1980, 1985).

Em resumo, para Skinner o propósito da ciência como um todo é criar condições para a ação efetiva, o que significa aumentar a probabilidade de ocorrência de conseqüências reforçadoras. Já o propósito da ciência do comportamento é produzir conhecimento pelo qual possamos prever e controlar o seu objeto de estudo (condições necessárias para ação efetiva nesse contexto). Desse modo, não é de interesse do behaviorismo radical discorrer sobre a natureza substancial do mundo, pois de nada vale saber qual é a substância que o compõe, já que há nesse mundo comportamento, e é no comportamento enquanto processo que devemos buscar as explicações para diversos problemas, tais como o problema da representação, do conhecimento e dos agentes internos causadores do comportamento. O ponto central, portanto, reside no caráter relacional do comportamento. Não é importante falar de "matéria" porque o que define o comportamento é a relação e não a substância que o compõe (Zilio, 2009). Para Skinner (1953/1965) o comportamento "é um processo, e não uma coisa" (p. 15).

O relacionismo por detrás da definição de comportamento interdita qualquer abordagem puramente substancial em sua caracterização. Já os objetivos práticos que definem a filosofia da ciência behaviorista radical tornam desnecessárias as investigações acerca da substância que compõe o comportamento, pois é possível explicar o comportamento, a ponto de prevê-lo e controlá-lo, sem fazer referência a elas. Além disso, discussões metafísicas sobre a natureza substancial do mundo são irrelevantes quando levamos em conta os objetivos práticos da ciência proposta por Skinner.

\section{A importância da substância para o behaviorismo radical}

Em que sentido, então, a substância seria importante para o behaviorismo radical? O caminho em direção a uma resposta positiva começa com a seguinte passagem de Skinner (1935/1961b): "Deve haver propriedades definidoras tanto do lado do estímulo quanto da reposta; caso contrário, nossas classes não terão referência necessária aos aspectos reais do comportamento" (p. 355, itálico adicionado). Trata-se de um trecho do artigo em que o autor pela primeira vez discorreu sobre a natureza genérica dos conceitos que fazem parte de sua ciência. Skinner (1935/1961b) estava enfrentando um dilema: por um lado era preciso que os estímulos e as respostas fossem passíveis de descrição por meio de suas propriedades físicas, já que são essas propriedades que os alocam na realidade empírica; por outro lado, a descrição baseada puramente nas propriedades físicas poderia transgredir a natureza relacional dos conceitos e do processo comportamental. A saída do autor (1935/1961b) está na concepção de classes comportamentais (Kitchener, 1977; Schnaitter, 1984).

Ao tratarmos de classes de eventos comportamentais não transgredimos o relacionismo e nem deixamos de lado as propriedades físicas que os tornam "reais". A questão é relativamente simples: quando descrevemos uma contingência utilizamos a linguagem fisicalista substancial para caracterizar os termos envolvidos. Por exemplo, dizemos "luz acesa", "pressionar a barra com a pata" e "pelota de comida". Em nosso próprio comportamento verbal utilizamos as propriedades físicas constitutivas dos eventos para descrevê-los. Ora, como poderíamos descrever o estímulo discriminativo "luz acesa" a não ser pela sua propriedade física e, portanto, substancial, de ser uma luz acesa? Outro modo de descrição é inconcebível. De nada adianta permanecer apenas no nível descritivo funcional porque dessa forma só teríamos conceitos vazios. Nem mesmo poderíamos afirmar que há um estímulo, que há uma resposta e que há uma conseqüência, pois a pergunta que se seguiria seria “Onde há?" e não é possível ir adiante com nosso discurso puramente funcional para responder essa questão. Precisamos do vocabulário substancial para alocar a relação na realidade - precisamos substancializar a relação (cf. Tonneau, 2005a).

A noção de classes comportamentais é importante porque, ao mesmo tempo em que permite que os conceitos da ciência do comportamento sejam descritos pelas suas propriedades físicas, também mantém a natureza relacional do processo. Isto é, ela estabelece um ponto de equilíbrio entre discurso substancial e discurso relacional que é imprescindível para a ciência do comportamento. Embora descrevamos um estímulo discriminativo pela sua propriedade física "luz acesa" não é a propriedade de ser uma luz acesa que o torna estímulo discriminativo, mas sim as contingências das quais ele faz parte. É na relação que a luz acesa se torna um estímulo discriminativo, mas é graças às suas propriedades físicas que é possível concebê-la como estímulo discriminativo. Talvez seja por isso que Skinner faz comentários tais como: "Os eventos que afetam um organismo devem ser passíveis de descrição na linguagem da ciência física" (1953/1965, p. 36); e "Uma análise experimental descreve o estímulo na linguagem da física" (1966b, p. 215). É possível observar, inclusive, que há uma concatenação entre a importância da descrição fisicalista e os propósitos da ciência do comportamento na seguinte passagem de Skinner (1938/1966a): "Um dos objetivos da ciência é provavelmente a exposição de todo o conhecimento em uma única 'linguagem'. [...] Outro é a predição e controle dentro de uma única área" (pp. 428-429). O behaviorismo radical é fiel aos dois objetivos. A predição e controle do comportamento configuram os objetivos principais da ciência behaviorista radical e, ainda que as propriedades físicas descritas não sejam os aspectos demarcatórios das relações funcionais, podemos dizer seguramente que Skinner estava preocupado em manter o vocabulário substancialista na descrição dos eventos estudados por sua ciência.

A importância da substância no behaviorismo radical, contudo, vai um pouco mais além. Skinner sempre se referiu à ciência do comportamento como parte das ciências naturais. Em suas palavras: "Ela é, eu assumo, parte da biologia. O organismo que se comporta é o organismo que respira, digere, engravida, faz gestação, e assim por diante" (1975, p. 42); e "Observar uma pessoa se comportar [...] é como observar qualquer sistema físico ou biológico" (1956/1961d, p. 206). Portanto, a ciência do comportamento deveria tratar de todos os fenômenos que dela são próprios a partir do vocabulário da ciência natural: o vocabulário fisicalista. É por isso que Skinner é cuidadoso em sempre ressaltar que os eventos estudados pela ciência do comportamento são eventos físicos. Se fosse de outra forma, a ciência do comportamento não 
seria uma "ciência natural". Esse cuidado é bastante evidente quando o autor trata dos eventos privados: "Mas eu mantenho que minha dor de dente é tão física quanto minha máquina de escrever, embora não pública" (1945/1961c, p. 285); "Um evento privado pode ser distinguido pela acessibilidade limitada, mas não [...] por alguma estrutura ou natureza especial" (1953/1965, p. 257); "Mas não se segue que essa parte particular [a privacidade] tenha qualquer propriedade física ou não-física especial” (1954, p. 304); “[...] os eventos observados através da introspecção são fisiológicos (todo comportamento é fisiológico)" (1979, p. 295); e, finalmente:

A objeção behaviorista não é primeiramente à natureza metafísica da substância mental. Eu acolho a posição, claramente favorável entre psicólogos e fisiologistas e de modo nenhum estranha à filosofia, de que o que nós observamos introspectivamente, assim como o que sentimos, são estados do nosso corpo". (1975, p. 44)

Essa última passagem é especialmente importante, pois coloca a ontologia da substância em relação direta com o posicionamento behaviorista radical: o comportamento, seja privado ou público, é um processo físico. Ademais, é possível supor que o comprometimento com as ciências naturais contribuiu, ainda que de maneira indireta, para que Skinner estabelecesse sua posição sobre a ontologia substancialista. Esse fato fica mais evidente, porém, em suas críticas ao behaviorismo metodológico.

A diferença fundamental entre behaviorismo radical e behaviorismo metodológico está na forma como as teorias avaliam os eventos privados: "A distinção entre público e privado não é, de modo algum, a mesma que entre físico e mental. É por isso que o behaviorismo metodológico (que aceita a primeira) é muito diferente do behaviorismo radical (que elimina o último termo da segunda)" (Skinner, 1945/1961c, p. 285). Em síntese, para o behaviorismo metodológico, público denota físico e privado denota mental e, para o behaviorismo radical, público e privado são eventos comportamentais diferenciados pela forma como se entra contato com os estímulos e não pela natureza constitutiva desses eventos (Skinner, 1945/1961c, 1953/1965, 1963, 1969a, 1974, 1975), o que significa que é errado fundamentar a dicotomia físico-mental a partir da dicotomia público-privado (Day, 1983/1992; Leigland, 1997; Moore, 1980, 2008).

Outro ponto importante é que a forma como o behaviorismo metodológico coloca a questão acaba por resultar na defesa implícita do dualismo mente-corpo (Day, 1983/1992; Leigland, 1997; Moore, 1981, 1999, 2008; Zuriff, 1995). Para o behaviorismo metodológico, não é viável estudar os eventos privados porque eles não são passíveis de verificação objetiva e, por essa razão, o valor de verdade das análises não pode ser atribuído consensualmente pelos cientistas. Trata-se do argumento positivista lógico segundo o qual as condições de verificação dos termos psicológicos devem ser comportamentos físicos e observáveis publicamente (e.g., Hempel, 1935/2000). Nas palavras de Skinner (1953/1965): "Outra solução proposta ao problema da privacidade é que há eventos públicos e privados e que os últimos não possuem lugar na ciência porque a ciência requer concordância entre os membros da comunidade" (pp. 281-282). O problema com essa "solução", continuando com Skinner (1953/1965), é o seguinte: "Longe de evitar a distinção tradicional entre mente e matéria, ou entre experiência e realidade, na verdade essa visão a encoraja. Ela assume que há, de fato, um mundo subjetivo que está além do alcance da ciência” (p. 282).

Não é errado, portanto, defender que o âmago da distinção entre behaviorismo radical e behaviorismo metodológico está no fato de que o primeiro não deixa nenhum fenômeno comportamental de fora de sua análise, mesmo que esse fenômeno seja observável apenas ao ser que se comporta, e faz isso porque, a partir de seu posicionamento naturalista, todos os fenômenos comportamentais devem ser necessariamente vistos como fenômenos físicos. E mais, todos os fenômenos naturais estão ao alcance das ciências naturais e, por esse motivo, negar o estudo dos eventos privados por causa de sua inacessibilidade pode sugerir uma dualidade de natureza substancial entre mente e matéria - não é por ser privado que um fenômeno deve ser banido como objeto de estudo das ciências naturais. Skinner (1945/1961c), ao discutir sobre esse problema do behaviorismo metodológico, apresenta a seguinte conclusão: “O que esta faltando [ao behaviorismo metodológico] é a corajosa e excitante hipótese behaviorista de que o que uma pessoa observa e fala sobre é sempre o mundo 'real' ou 'físico' (ou, ao menos, o 'único' mundo)” (p. 284). Em poucas palavras, ao discorrer sobre as diferenças entre behaviorismo radical e behaviorismo metodológico e ao se comprometer com as ciências naturais, Skinner inevitavelmente se valeu do discurso substancialista e apresentou, assim, comprometimentos ontológicos substancialistas.

Também é possível notar a importância da substância para o behaviorismo radical quando Skinner discorre sobre o papel da fisiologia na explicação do comportamento: preencher as lacunas inerentes à análise essencialmente histórica proposta pelo behaviorismo radical. Isto é, o papel da fisiologia seria o de preencher as lacunas espaciais entre o comportamento e as variáveis das quais ele é função e as lacunas temporais entre os efeitos do ambiente sobre os organismos e as modificações conseguintes de seu comportamento (cf. Skinner, 1953/1965, p. $54 ; 1956 / 1961$ d, p. $214 ; 1969$ b, p. $24 ; 1974$, p. $214-215$; 1975 , p. $43 ; 1985$, p. 297 ; 1987, p. $782 ; 1988$, p. 470).

Em linhas gerais, as histórias filogenéticas e ontogenéticas dos organismos são substancializadas pelas suas modificações fisiológicas. Um organismo que passou por uma história de condicionamento é um organismo fisiologicamente modificado. Nesse caso, "a fisiologia estuda o produto enquanto as ciências da variação e seleção estudam a produção. [...] A fisiologia nos diz como o corpo funciona; as ciências da variação e seleção nos dizem por que ele é um corpo que funciona dessa forma" (Skinner, 1990, p. 1208).

Mas não é só no âmbito metodológico que a análise substancial da fisiologia traz informações relevantes para a análise relacional do behaviorismo radical. A própria relação depende da substância. Essa constatação pode parecer óbvia, mas há uma grande diferença entre aceitar o auxílio metodológico da fisiologia para o preenchimento de lacunas da ciência do comportamento e postular a dependência existencial do comportamento perante a estrutura fisiológica. Em diversas passagens Skinner parece sustentar a segunda tese: "O fisiologista estuda estruturas e processos sem os quais o comportamento não poderia ocorrer” (1963, p. 957); "Não 
há dúvidas sobre a existência de órgãos dos sentidos, nervos e cérebros ou sobre suas participações no comportamento" (1969b, p. 25); "Dizem que os [behavioristas radicais] estão interessados no controle do comportamento, mas não em entender os mecanismos por ele responsáveis. Eu tenho certeza de que há mecanismos, mas eles pertencem a uma disciplina diferente - fisiologia" (1983, p. 15); e "Todo o comportamento é devido aos genes, alguns mais ou menos diretamente, e o restante por meio do papel dos genes na produção das estruturas que são modificadas durante o tempo de vida do indivíduo" (1988, p. 430). Concluindo com Skinner (1969b):

Seria mais fácil enxergar como os fatos fisiológicos e comportamentais estão relacionados se nós tivéssemos uma explicação completa do organismo que se comporta - tanto do comportamento observável quanto dos processos fisiológicos que ocorrem ao mesmo tempo. [...] O organismo seria visto como um sistema unitário, e seu comportamento claramente como parte de sua fisiologia. (p. 60)

A complementaridade entre fisiologia e análise do comportamento não se restringe apenas ao nível metodológico, mas se estende à própria existência do comportamento: não há comportamento sem substância; especificamente, não há comportamento sem substância física. A evolução do comportamento é acompanhada inextricavelmente pela evolução de estruturas fisiológicas que tornam o comportamento possível. Skinner (1974) observa que "o comportamento ocorre porque mecanismos apropriados foram selecionados no decorrer da evolução" (p. 47). Não há comportamento operante, por exemplo, sem um organismo cuja estrutura fisiológica torna possível a seleção pelas conseqüências.

\section{Relacionismo substancial: a ontologia presente no behaviorismo radical}

Baseando-se no que foi até agora escrito, é possível apresentar uma síntese do posicionamento de Skinner acerca da substância. Posicionamento esse que, por sua vez, servirá de fundamento para uma ontologia que seja plenamente compatível com o behaviorismo radical. Em resumo, a substância parece não ser importante pelos seguintes motivos: (1) Metafisica ausente: o behaviorismo radical não precisa prestar contas às discussões metafísicas, pois qualquer que seja o resultado dessas discussões, ele não falseará o fato de que é possível controlar e prever efetivamente o comportamento com o auxílio do conhecimento produzido pela ciência behaviorista radical; (2) Propósitos da ciência: se o objetivo da ciência é prever e controlar o seu objeto de estudo, não é preciso ir além do nível de análise comportamental (relacional) para cumpri-lo. Esse é um dos motivos que levou Skinner (1938/1966a) a declarar independência da análise do comportamento perante a fisiologia. Afinal, é possível prever e controlar o comportamento sem levar em conta a estrutura fisiológica do organismo que se comporta; e (3) Relacionismo: o comportamento é relação e, enquanto tal, não pode ser definido como substância.

Por outro lado, a substância é importante pelos seguintes motivos: (1) Conceitos genéricos: o vocabulário substancial aloca os conceitos genéricos da ciência do comportamento na realidade observável e manipulável. É impossível conceber a própria existência de estímulos e respostas sem fazer referências às propriedades físicas que os compõem; (2) Vocabulário unificado: o vocabulário das ciências naturais é invariavelmente substancial, já que se refere às coisas e aos eventos físicos do mundo, então o behaviorismo radical e a ciência que ele embasa, a análise do comportamento, devem descrever seu objeto de estudo a partir desse mesmo vocabulário se almeja fazer parte das ciências naturais; (3) Contraposição ao behaviorismo metodológico: a negação da dualidade físico-mental e a defesa da dualidade público-privado são fundadas nas teses de que há apenas uma substância - a física - e de que a diferença entre público e privado é relacional. Dispensar os eventos privados do estudo científico, tal como os behavioristas metodológicos o fazem, pode acarretar o fortalecimento da dualidade físico-mental, inaceitável pelo behaviorismo radical; (4) Estabelecimento do behaviorismo radical como ciência natural: o objeto de estudo do behaviorismo radical deve fazer parte do mundo natural, que é o mundo físico, o único mundo que existe; (5) Auxílio metodológico: a fisiologia preencherá as lacunas deixadas pela explicação essencialmente histórica da análise do comportamento behaviorista radical; (6) Existência do comportamento: só há comportamento porque há estruturas fisiológicas que tornam a sua existência possível.

É possível supor que para o behaviorismo radical tanto a substância quanto a relação são imprescindíveis. Embora Skinner apresente o behaviorismo radical essencialmente como a filosofia da ciência das relações, ou seja, do comportamento, essa ciência não é possível sem substância. Esse fato nos remete a uma interpretação menos radical das negativas de Skinner acerca da ontologia substancialista. Quando afirma que o termo "matéria" perdeu sua importância porque há no mundo comportamento, Skinner parece estar apenas dizendo que não podemos ignorar a relação - é impossível estudar o comportamento apenas pela óptica substancialista. Quando, por sua vez, Skinner defende que devemos nos manter no nível de análise comportamental, a justificativa parece ser apenas a de que essa atividade já é suficiente para prever e controlar o comportamento. $\mathrm{O}$ argumento da "metafísica ausente", segundo a qual seria possível fazer ciência do comportamento sem comprometimentos metafísicos, é outro indício das prescrições práticas que controlam o comportamento dos cientistas do comportamento: produzir conhecimento científico a fim de controlar e prever o seu objeto de estudo e, assim, promover condições para a ação efetiva.

Nota-se que todas as negativas são fundamentadas pelo caráter prático que norteia o behaviorismo radical em sua filosofia da ciência e em suas práticas científicas. Sendo assim, elas não impedem a postulação de uma posição ontológica positiva do behaviorismo radical acerca da substância, mas apenas deixam claro que, a despeito do resultado, este não influirá na autonomia da ciência do comportamento no que diz respeito às suas estratégias de previsão e controle do seu objeto de estudo. De fato, todos os indícios sobre a importância da substância sugerem que há no behaviorismo radical comprometimento com a ontologia substancialista; comprometimento que abarca a defesa da existência do mundo real como sendo o mundo físico e/ou o mundo natural. 
Sendo assim, o relacionismo radical não reflete com acurácia a ontologia behaviorista radical.

Continuemos, então, com o nosso exercício metafísico. O ponto de partida da ontologia behaviorista radical pode ser expresso com a seguinte passagem de Skinner (1967): “O behaviorismo começa com a hipótese de que o mundo é feito de apenas um tipo de substância - lidada com muito sucesso pela física. [...] Os organismos fazem parte desse mundo, e os seus processos são, por esse motivo, processos físicos" (p. 325). Nesse sentido, o behaviorismo radical é monista fisicalista. Há apenas um tipo de substância no mundo: a substância física. Esse comprometimento ontológico está de acordo com a importância dada por Skinner à substância. $\mathrm{O}$ monismo fisicalista, naturalmente, é a antípoda do dualismo cartesiano e podemos encontrar passagens em que Skinner nega veementemente a existência de uma mente imaterial: "Nenhum tipo especial de substância mental é pressuposta [no behaviorismo radical]" (1974, p. 220); "Eu prefiro a posição do behaviorismo radical em que a existência de entidades subjetivas é negada" (1979, p. 117) e, em tom mais ameno, “Embora eu não negue a 'existência de eventos mentais', eu não acredito que eles existam" (1988, p. 212). Concluindo com Skinner (1974):

Uma análise do comportamento não apenas não rejeita qualquer um desses "processos mentais superiores"; ela [também] tem conquistado a dianteira na investigação das contingências sob as quais eles ocorrem. O que ela rejeita é a suposição de que atividades comparáveis ocorrem no misterioso mundo da mente. (p. 233)

Assim temos o primeiro ponto esclarecido: com relação à natureza substancial do mundo, o behaviorismo radical é monista fisicalista. Seria desastroso, porém, se parássemos aqui na delineação da ontologia behaviorista radical, pois no mundo constituído por substância física há organismos que se comportam. Continuando com Skinner (1979): “O argumento behaviorista não é o do materialista ingênuo que afirma que o 'pensamento é uma propriedade da matéria em movimento', nem é dele [do behaviorista] a reivindicação da identidade do pensamento ou dos estados conscientes com os estados [cerebrais] materiais" (p. 117). O que essa passagem sugere? Uma interpretação possível é que há comportamento no mundo físico; e que o comportamento é, enquanto relação, irredutível à substância. Se restringirmos a ontologia behaviorista radical apenas à sua contraparte substancial, também privamos o comportamento de sua essência relacional, o que significa, sem exageros, que eliminamos o comportamento tal como definido pelo behaviorismo radical: como um processo relacional de fluxo contínuo (Skinner, 1953/1965, 1954) cuja existência é base fundamental e pressuposta para toda a construção da teoria do comportamento behaviorista radical (Zilio, 2009). A conseqüência última de se ater apenas à substância seria, então, a própria negação do behaviorismo radical. Dessa forma, a ontologia behaviorista radical é, em um só tempo, substancial $e$ relacional: há um mundo físico e há nesse mundo comportamento.

A tese defendida neste ensaio, portanto, é a de que a substância e a relação devem ser imanentes na ontologia behaviorista radical. Tais categorias não devem ser vistas como disjuntivas, pois não há incompatibilidade, ameaças ou concorrência entre elas; pelo contrário, há complementaridade. Enfim, o nosso objetivo era desvendar o posicionamento ontológico acerca do comportamento mais condizente com o behaviorismo radical. Tal ontologia pode ser assim exposta: o comportamento é relação, mas é relação que ocorre no mundo físico. Não há comportamento sem relação, pois comportamento é relação, mas, por outro lado, não há relação sem substância. A essa tese ontológica sugere-se o nome de relacionismo substancial.

Cabe finalizarmos o ensaio com a seguinte questão: e daí? Após esse longo percurso chegamos a uma tese metafísica sobre a ontologia do comportamento que parece estar de acordo com o behaviorismo radical, mas quais seriam as conseqüências do relacionismo substancial para os analistas do comportamento? Que conseqüências podemos esperar desse exercício metafísico? É possível sugerir uma resposta a partir de uma definição "pragmatista" da função da metafísica. Para Krägeloh (2006), "hipóteses ontológicas são, pragmaticamente, prescrições metodológicas disfarçadas" (p. 331). Isto é, o exercício metafísico é comportamento verbal e pode, enquanto tal, servir de base para a criação de regras da conduta científica.

O distanciamento do behaviorismo radical da ontologia substancialista pode, por exemplo, servir de argumento para a diminuição da relevância da fisiologia, sobretudo das neurociências, para o estudo do comportamento (e.g. Reese, 1996). Nota-se que agora não estamos mais lidando com questões metafísicas per se, e sim com a possibilidade de diálogo entre ciências que, por sua vez, pode ser influenciada por posições metafísicas. De todo modo, parece não haver problemas com a diminuição da importância da fisiologia para o estudo do comportamento no contexto metafísico do relacionismo radical. Pelo contrário, o relacionismo radical parece, inclusive, encorajá-la, já que a única propriedade essencial do comportamento seria a relação que o define. Entretanto, quando assumimos que tanto a substância quanto a relação são categorias ontológicas essenciais à existência do comportamento, essa diminuição parece absurda. Só uma síntese entre a análise do comportamento e a ciência dos mecanismos fisiológicos responsáveis pelo comportamento será capaz de oferecer uma explicação completa do organismo que se comporta (Skinner, 1969b). Afinal, a própria existência do fenômeno é, em um só tempo, substancial e relacional.

\section{Referências}

Abib, J. A. D. (2001). Arqueologia do behaviorismo radical e o conceito de mente. In H. J. Guilhardi (Ed.), Sobre comportamento e cognição (pp. 20-35). Santo André: Esetec Ed. Associados.

Abib, J. A. D. (2004). O que é comportamentalismo? In M. Zilah, et al. (Ed.), Sobre comportamento e cognição (pp. 52-61). Santo André : Esetec Ed. Associados.

Barnes, D., \& Roche, B. (1994). Mechanistic ontology and contextualistic epistemology: a contradiction within behavior analysis. The Behavior Analyst, 17(1), 165-168.

Barnes, D., \& Roche, B. (1997). A behavior-analytic approach to behavioral reflexivity. Psychological Record, 47(4), 543-572. 
Barnes-Holmes, D. (2000). Behavioral pragmatism: no place for reality and truth. The Behavior Analyst, 23(2), 191-202.

Barnes-Holmes, D. (2005). Behavioral pragmatism is a-ontological, not antirealist: a reply to Tonneau. Behavior and Philosophy, 33, 67-79.

Baum, W. M. (1999). Compreender o behaviorismo: ciência, comportamento e cultura (M. Silva, Trad.). Porto Alegre: Artmed Editora (Trabalho original publicado em 1994).

Bjork, D. (1993). B. F. Skinner: a life. New York: Basic Books.

Carrara, K. (2005). Behaviorismo radical: crítica e metacrítica (2. ed). São Paulo: Editora Unesp.

Carvalho Neto, M. B. (2001). B. F. Skinner e as explicações mentalistas para o comportamento: uma análise históricoconceitual (1931-1959). Tese de Doutorado, Universidade de São Paulo, São Paulo.

Chiesa, M. (1994). Radical behaviorism: the philosophy and the science. Boston: Authors Cooperative, Inc., Publishers.

Churchland, P. S. (1986). Neurophilosophy: toward a unified science of mind-brain. Cambridge: The MIT Press.

Day, W. (1992). On the difference between radical behaviorism and methodological behaviorism. In S. Leigland (Ed.), Radical behaviorism: Willard Day on psychology and philosophy (pp. 61-72). Nevada: Context Press (Trabalho original publicado em 1983).

Descartes, R. (1984). Meditations on first philosophy and Objections and replies. In J. Cottingham, R. Stoothoff, \& D. Murdoch (Eds.), The philosophical writings of Descartes (Vol. 2). Cambridge: Cambridge University Press (Trabalho original publicado em 1641).

Hamlyn, D. W. (1995). History of metaphysics. In T. Honderich (Ed.), The Oxford Companion to Philosophy (pp. 556-559). New York: Oxford University Press.

Hayes, L. J. (1997). Scientific knowing in psychological perspective. In L. J. Hayes, \& P. M. Ghezzi (Eds.), Investigations in behavioral epistemology (pp. 123-141). Nevada: Context Press.

Hayes, S. C., \& Brownstein, A. J. (1986). Mentalism, BehaviorBehavior Relations, and a Behavior-Analytic View of the Purposes of Science. The Behavior Analyst, 9(2), 175-190.

Hempel, C. G. (2000). The logical analysis of psychology. In R. Jeffrey (Org.), Carl G. Hempel: selected philosophical essays (pp. 165-180) Cambridge: Cambridge University Press (Trabalho original publicado em 1935).

Hocutt, M. (1996). Behaviorism as opposition to cartersianism. In W. O'Donohue, \& R. F. Kitchener (Eds.), The Philosophy of psychology (pp. 81-95). London: Sage Publications.

Inwagen, P. V. (2007). Metaphysics. Stanford Encyclopedia of Philosophy. Retrieved from http://plato.stanford.edu/entries/ metaphysics

Kitchener, R. F. (1977). Behavior and behaviorism. Behaviorism $5,11-71$.

Krägeloh, C. U. (2006). Pragmatism and a-ontologicalism in a science of behavior. The Behavior Analyst Today, 7(3), 325334.

Leigland, S. (1997). Systems and theories in behavior analytic science: an overview of alternatives. In L. J. Hayes, \& P. M. Ghezzi (Eds.), Investigations in behavioral epistemology (pp. 11-31). Nevada: Context Press.

Leigland, S. (2004). Pragmatism and radical behaviorism: comments on Malone (2001). Behavior and Philosophy, 32, 305-312.
Lowe, E. J. (1995). Ontology. In T. Honderich (Ed.), The Oxford Companion to Philosophy (pp. 634-635). New York: Oxford University Press.

Moore, J. (1980). On behaviorism and private events. The Psychological Record, 30, 459-475.

Moore, J. (1981). On mentalism, methodological behaviorism, and radical behaviorism. Behaviorism, 9, 55-67.

Moore, J. (1984). On behaviorism, knowledge, and causal explanation. Psychological Record, 34, 73-97.

Moore, J. (1994). On introspections and verbal reports. In S. Hayes, L. Hayes, M. Sato, \& K. Ono (Eds.), Behavior analysis of language and cognition (pp. 281-299). Nevada: Context Press.

Moore, J. (1999). The basic principles of behaviorism. In B. A. Thyer (Ed.), The philosophical legacy of behaviorism (pp. 41-68). London: Kluwer Academic Publishers.

Moore, J. (2008). Conceptual foundations of radical behaviorism. New York: Sloan Publishing.

Moore, J. (2010). Behaviorism and the stages of scientific activity. The Behavior Analyst, 33, 47-63.

Moxley, R. A. (2001a). The modern/postmodern context of Skinner's selectionist turn in 1945. Behavior and Philosophy, 29, 121-153.

Moxley, R. A. (2001b). Sources for Skinner's pragmatic selectionism in 1945. The Behavior Analyst, 24(2), 201-212.

Moxley, R. A. (2002a). Some more similarities between Peirce and Skinner. The Behavior Analyst, 25(2), 201-214.

Moxley, R. A. (2002b). The selectionist meaning of C. S. Peirce and B. F. Skinner. The Analysis of Verbal Behavior, 18, 71-91.

Moxley, R. A. (2004). Pragmatic selectionism: the philosophy of behavior analysis. The Behavior Analyst Today, 5(1), 108-125.

Reese, H. W. (1996). How is physiology relevant to behavior analysis? The Behavior Analyst, 19(1), 61-70.

Robinson, H. (2009). Substance. Stanford Encyclopedia of Philosophy. Retrieved from http://plato.stanford.edu/entries/ substance

Schnaitter, R. (1984). Skinner on the "mental" and the "physcial". Behaviorism, 12(1), 1-14.

Skinner, B. F. (1954). Critique of psychoanalytic concepts and theories. The Scientific Monthly, 79(5), 300-305.

Skinner, B. F. (1961a). The concept of reflex in the description of behavior. In B. F. Skinner (Ed.), Cumulative record: a selection of papers ( $2^{\mathrm{a}}$ ed., pp. 319-346). New York: Appleton-CenturyCrofts. (Trabalho original publicado em 1931).

Skinner, B. F. (1961b). The generic nature of the concepts of stimulus and response. In B. F. Skinner (Ed.), Cumulative record: a selection of papers ( $2^{\mathrm{a}}$ ed., pp. 347-366). New York: Appleton-Century-Crofts. (Trabalho original publicado em 1935).

Skinner, B. F. (1961c). The operational analysis of psychological terms. In B. F. Skinner (Ed.), Cumulative record: a selection of papers ( $2^{\mathrm{a}}$ ed., pp. 272-286). New York: Appleton-CenturyCrofts (Trabalho original publicado em 1945).

Skinner, B. F. (1961d). What is psychotic behavior? In B. F. Skinner (Ed.), Cumulative record: a selection of papers $\left(2^{\mathrm{a}} \mathrm{ed} ., \mathrm{pp} .202-\right.$ 219). New York: Appleton-Century-Crofts (Trabalho original publicado em 1956).

Skinner, B. F. (1963). Behaviorism at fifty. Science, New Series, 140(3570), 951-958.

Skinner, B. F. (1965). Science and human behavior. New York: The Free Press (Trabalho original publicado em 1953). 
Skinner, B. F. (1966a). The behavior of organisms: an experimental analysis. New York: Appleton-Century-Crofs (Trabalho original publicado em 1938).

Skinner, B. F. (1966b). What is the experimental analysis of behavior? Journal of the Experimental Analysis of Behavior, 9(3), 213-218.

Skinner, B. F. (1967). The problem of consciousness - a debate. Philosophy and Phenomenological Research, 27(3), 325-337.

Skinner, B. F. (1969a). Contingencies of reinforcement: a theoretical analysis. New York: Appleton-Century-Crofts.

Skinner, B. F. (1969b). The machine that is man. Psychology Today, 2, 20-25, 60-63.

Skinner, B. F. (1974). About behaviorism. New York: Alfred A. Knopf.

Skinner, B. F. (1975). The steep and thorny way to a science of behavior. American Psychologist, 30(1), 42-49.

Skinner, B. F. (1979). The shaping of a behaviorist: part two of an autobiography. New York: Alfred A. Knopf.

Skinner, B. F. (1981). Selection by consequences. Science, New Series, 213(4507), 501-504.

Skinner, B. F. (1983). Can the experimental analysis of behavior rescue psychology? The Behavior Analyst, 6, 9-17.

Skinner, B. F. (1985). Cognitive science and behaviourism. British Journal of Psychology, 76, 291-301.

Skinner, B. F. (1987). Whatever happened to psychology as the science of behavior? American Psychologist, 42(8), 780-786.

Skinner, B. F. (1988). In A. C. Catania, \& S. Harnad (Eds.), The selection of behavior: the operant behaviorism of B.F. Skinner: comments and consequences. New York: Cambridge University Press.

Skinner, B. F. (1990). Can psychology be a science of mind? American Psychologist, 45(11), 1206-1210.

Smith, L. D. (1986). Behaviorism and logical positivism: a reassessment of the alliance. Stanford: Stanford University Press.
Smith, L. D. (1992). On prediction and control: B. F. Skinner and the technological ideal of science. American Psychologist, $47(2), 216-223$.

Tonneau, F. (2005a). Antirealist arguments in behavior analysis. Behavior and Philosophy, 33, 55-65.

Tonneau, F. (2005b). Behavior analysis, common sense, and logic: reply to Barnes-Holmes. Behavior and Philosophy, 33, 81-84.

Zilio, D. (2009). A natureza comportamental da mente: behaviorismo radical e filosofia da mente. Dissertação de Mestrado, Universidade Estadual Paulista - UNESP, Marília.

Zilio, D. (2010). Fisicalismo na filosofia da mente: definição, estratégias e problemas. Ciências \& Cognição, 15(1), 217-240.

Zuriff, G. E. (1975). Where is the agent in behavior? Behaviorism, $3(1), 1-21$.

Zuriff, G. E. (1980). Radical behaviorist epistemology. Psychological Bulletin, 87(2), 337-350.

Zuriff, G. E. (1985). Behaviorism: a conceptual reconstruction. New York: Columbia University Press.

Zuriff, G. E. (1995). A review of Baum's Understanding Behaviorism: Science, Behavior, and Culture. The Behavior Analyst, 18(2), 395-400

Zuriff, G. E. (2003). Science and human behavior, dualism, and conceptual modification. Journal of the Experimental Analysis of Behavior, 80(3), 345-352.

Recebido em 02.02.2010

Primeira decisão editorial em 18.10.2010

Versão final em 09.11.2010

Aceito em 02.12.2010 